\title{
O SENTIDO DO POLÍTICO NA CONCEPÇÃO DO TRANSCONSTITUCIONALISMO: UMA PERSPECTIVA SOCIOLÓGICA*
}

\author{
THE SENSE OF POLICY IN DESIGNING \\ TRANSCONSTITUTIONALISM: A SOCIOLOGICAL \\ PERSPECTIVE
}

\begin{abstract}
RESUMO: a questão de saber se existem ou não constituições além das oferecidas pelo Estado tem sido tema central nos debates acadêmicos das últimas décadas. Essa contribuição deriva do insight histórico de que sempre existiram formas extensas de ordenação social com o crivo de constitucional, seja abaixo, ao lado ou acima do Estado. Nas últimas décadas, o debate sobre o constitucionalismo além do Estado se desdobrou em dois discursos: o primeiro foca em organizações públicas internacionais e, o outro, foca em estruturas privadas. O primeiro é dirigido principalmente por cientistas políticos e juristas e se caracteriza por retrabalh ar os conceitos estatais do político, a fim de torná-los compatíveis com os desenvolvimentos transnacionais. Por outro lado, o segundo, minimiza sistematicamente a dimensão política das estruturas transnacionais. A fim de colmatar esta lacuna, estão sendo desenvolvidas várias dimensões-chave para um conceito transnacional específico do político
\end{abstract}

Palavras-chave: Constitucionalismo. Lei global. Transparência. Prestação de contas. Sociedade mundial.
ABSTRACT: The question whether constitutions exists or can exist at all beyond the state has been a central theme of academic dispute in the last decades. This contribution departs from the historical insight that extensive forms of ordering possessing constitutional qualities always have existed beneath, beside and above the state. In the last decades the debate on constitutionalism beyond the state has however unfolded in two separate discourses: One which focuses on public international organizations and another which focuses on private structures. The former is mainly driven by political scientists and public lawyers and is characterized by an attempt to rework nation state concepts of the political in order to make them compatible with transnational developments. The latter is, on the other hand, systematically downplaying the political dimension of transnational structures. In order to bridge this gap a number of key dimensions of a specific transnational concept of the political is being fleshed out.

Keywords: Constitutionalism. Global law. Transparency. Accountability. World society.

\footnotetext{
* Artigo ampliado do publicado em: JORGES, Christian; RALLI, Tommi (ed.). After Globalization - New Patterns of Conflict and their Sociological and Legal Reconstruction. Oslo: Arena, 2011. p. 285-321.

${ }^{1}$ Professor da Copenhagen Business School. Ph.D. em Direito (European University Institute, Florence, 2008). Habilitação em Sociologia do Direito (Goethe University, Frankfurt am Main, 2014).
} 


\section{INTRODUÇÃO: DOS DOIS DISCURSOS SOBRE O CONSTITUCIONALISMO TRANSNACIONAL}

Em 1815, no Congresso de Viena, iniciou-se o processo que levou à instituição da primeira organização pública internacional - Commission Centrale pour la Navigation du Rhin (CCNR, Comissão Central para a Navegação do Reno $)^{2}$. No mesmo ano foi publicado o primeiro volume de Friedrich Carl von Savigny's (1961), Geschichte des Römischen Rechts im Mittelalter. Essa obra funcionou como uma espécie de exercício preliminar, acarretando o desenvolvimento dos princípios essenciais do direito privado internacional moderno em seu Systems des heutigen Römischen Rechts (1840-49) (SAVIGNY, 1974). Esses dois movimentos ilustram que nem a transnacionalidade pública nem a privada constituem fenômeno novo. Indicam, principalmente, que a forma particular de Estado moderno materializada na époque dos enquadramentos da revolução francesa e americana nunca se sustentou, visto que sempre existiram estruturas substanciais de ordenamento operando abaixo, acima e paralelamente ao Estado. Mais ainda, analisando esses movimentos através de uma abordagem histórica, forçoso concluir que a consolidação do estado moderno implica mais - e não menos - transnacionalidade. Em outras palavras, a relação entre estado nação e as estruturas transnacionais tem sido sucessivamente caracterizada como uma relação de mútuo crescimento.

Apesar dessa relação intrínseca entre estado e transnacionalidade, essa última não pode ser compreendida apenas com base no direito internacional clássico e em modalidades de relações internacionais. Estruturas transconstitucionais não estão emergindo somente de maneira intermediária aos estados-nação, como uma forma de se chegar a uma limitação (Hegung) de conflitos interestaduais ${ }^{3}$. Ao revés, o espaço transnacional caracteriza-se por uma estrutura de direito próprio, a qual é reproduzida com base numa lógica independente. Por uma perspectiva sociológica, o espaço transnacional é visto como um conglomerado de estruturas próprias (Eigenstrukturen) (STICHWEH, 2006, p. 239-257; STICHWEH, 2008, p. 329-355) as quais reproduzem

\footnotetext{
${ }^{2}$ Ver, também, Christian Walter (2001, p. 176).

${ }^{3}$ Nesse sentido, ver, especialmente, Georg WF Hegel ([1821] 1968, p. 350) e Carl Schmitt (1950).
} 
independentes formas de padrões sociais. Nosso mundo é caracterizado por polos ou níveis de formação de estruturas plurais com distintas, porém interligadas, lógicas operantes de maneira simultânea (SASSEN, 2006; KJAER, 2010a). Essa pluralidade também é ilustrada pelo fato do Estado moderno atuar tão-somente como uma cobertura "no topo" de estruturas feudais pré-existentes. Estruturas feudais que, embora cada vez mais marginalizadas, continuam operando abaixo das estruturas dos Estados modernos, por exemplo, nas monarquias constitucionais, nos cargos herdados na Câmara dos Lordes e redes fechadas da nobreza ${ }^{4}$. Assim, além das estruturas feudais e do Estado moderno, a esfera transnacional deve ser entendida como um terceiro nível de reprodução de padrões sociais que se desdobram na sociedade mundial.

No entanto, as múltiplas camadas/níveis da sociedade mundial não são refletidas de maneira adequada na auto compreensão dominante das disciplinas acadêmicas de direito, sociologia e ciência política ${ }^{5}$. Essas disciplinas permanecem essencialmente centradas no Estado, de modo que são metodologicamente incapazes de captar o tipo de estrutura social reproduzida fora do domínio do Estado. De Hegel ([1821], 1968) a Bourdieu $(1989)^{6}$, a ênfase central sempre foi a totalidade do Estado. Assim, as modernas disciplinas de direito e de ciência social sabotaram sistematicamente qualquer tentativa de compreender profundamente as outras camadas da sociedade.

A relação entre o Estado-nação e as estruturas transnacionais, contudo, tem sofrido mudanças significativas desde meados do século XX (WALKER, 2008). Assim, o globo pode ter atingido um "ponto crítico" (SASSEN, 2006, p. 9), de maneira que a relação entre Estado e transnacionalidade encontra-se em profunda reconfiguração. Isso não significa que a configuração do Estado-nação estaria fadada ao desaparecer, mas que o status relativo à centralidade dos Estados-nação dentro da estrutura mais ampla da sociedade mundial está mudando. Assim, uma compreensão sociológica adequada da maneira pela qual a ordem social é produzida deverá se distanciar da ideia de que os

\footnotetext{
${ }^{4}$ Ver, por exemplo, Simon Deakin (2009, p. 53-73).

${ }^{5}$ A tendência a um nacionalismo metodológico, contudo, parece ser menos significativo na sociologia. Ver Daniel Chernilo (2007). Nesse mesmo sentido, Chernilo (2006).

${ }^{6}$ Ver, por exemplo, Pierre Bourdieu (1989).
} 
Estados representam apenas um modo de ordenação entre vários. Em vez disso, o mundo contemporâneo é caracterizado por duas formas dominantes de ordenação que dependem de dois princípios organizacionais diferentes: os Estados, que se baseiam em um princípio territorial de organização e, por outro lado, as formas contemporâneas de ordenação transnacional, as quais possuem, como princípio organizacional central, a diferenciação funcional. Além disso, as formas "tradicionais" pré-modernas de ordenação social baseadas na diferenciação segmentária continuam a desempenhar papel relevante. O desenvolvimento de uma perspectiva relacional voltada à compreensão das diferentes camadas da sociedade mundial e a multiplicidade de ordens sociais que operam tanto dentro como entre essas próprias camadas é, portanto, um dos desafios cruciais com os quais a teoria jurídica e social contemporânea se deparam.

De onde estamos agora, os Estados-nação territorialmente bem delineados, que, de certa maneira, foram internamente estabilizados através de formas organizacionais baseadas na estratificação como mecanismo central de inclusão/exclusão, e que até agora operavam com base na autoproclamada ideia de subordinação de todos os outros processos sociais ao Estado, parecem refletir uma forma de "semântica transitória". A modernidade clássica, de 1789 a 1898, caracterizou-se por um duplo movimento no qual a emergente sociedade funcionalmente diferenciada foi reestabilizada através do desenvolvimento de novas e distintas formas modernas de diferenciação territorial e estratificada dentro dos diferentes sistemas funcionais (KJ/ER, 2010b). Na medida em que a modernidade é definida como a primazia da diferenciação funcional (LUHMANN, 1997, p. 1143), é possível compreender os desenvolvimentos em curso como representação de uma radicalização da modernidade, uma vez que a expansão exponencial de estruturas transnacionais funcionalmente delineadas nas últimas décadas e a mudança do equilíbrio entre o nível Estado-nação e a camada transnacional indicam que a dependência da diferenciação funcional na sociedade mundial está se aprofundando. Os sistemas funcionais, por exemplo, da economia, da ciência, dos meios de comunicação, dos esportes e da educação libertam-se gradualmente de sua dependência interna de mecanismos de estabilização que se baseiam em formas de diferenciação territoriais e estratificatórias, iniciando, assim, uma ruptura qualitativa em face à modernidade 
clássica. Tanto estruturas públicas quanto privadas, assim como todos os tipos de estruturas híbridas (público-privadas) que se baseiam principalmente na diferenciação funcional tiveram nascimento (para citar algumas: ICANN para a Internet, OMS para a saúde e ISO para padrões de produtos). Portanto, mesmo que o sistema político na forma de Estado-nação provavelmente continue produzindo decisões coletivamente vinculantes, ele está sendo cada vez mais desmistificado, pois a capacidade de os Estados manterem a consciência essencialmente moderna inicial (séculos XVI e XVII) de que são entidades orgânicas ou holísticas que englobam a sociedade como um todo está sendo progressivamente abalada.

Particularmente, os sistemas político e jurídico caracterizavam-se por uma forte confiança interna nas delimitações territoriais da modernidade clássica. No entanto, em ambas as considerações, isso parece estar mudando. O surgimento de estruturas legais e políticas funcionalmente delineadas com um alcance verdadeiramente global ainda pode estar em um estágio embrionário, mas, pela primeira vez na história, tais estruturas surgiram na segunda metade do século XX. Ademais, a expansão contínua de tais estruturas parece ser uma previsão válida para as próximas décadas. Nesse sentido, é possível observar uma mudança semântica: "Direito global sem Estado" (TEUBNER, 1997), bem como "Democracia Cosmopolita" (ARCHIBUGI; HELD, 1995) tornaram-se expressões significativas, indicando que os sistemas legal e político também estão no processo de se libertar de sua confiança interna em mecanismos de estabilização territorialmente delineados na forma de Estados-nação.

Estruturas políticas e jurídicas transnacionais não implicam, contudo, uma simples transferência de formas de lei e política do Estado-nação para o domínio transnacional através da constituição de um estado mundial ou de qualquer outra forma de estrutura que apenas copie a forma e a função dos Estados-nação. As tentativas de justificar uma transferência personalizada das normas e das instituições do Estado-nação para o domínio transnacional só faz sentido se forem realizadas como uma reflexão filosófica sem qualquer fundamento sociológico ${ }^{7}$. Além disso, de uma perspectiva sociológica, é

\footnotetext{
${ }^{7}$ Para tal intento filosófico, ver Otfried Höffe (1999).
} 
impossível ignorar a composição estrutural profundamente diferente do espaço transnacional quando comparado com o domínio do Estado-nação.

A estrutura contemporânea do polo transnacional da sociedade mundial emergiu parcialmente através de uma metamorfose do tipo de estruturas interestaduais públicas e privadas, na forma de organizações internacionais públicas e do direito privado internacional baseado no Estado, que surgiram na modernidade clássica. Essas estruturas ganharam, acima de tudo, uma importância tamanha que não podem mais ser entendidas como meros reflexos de uma delegação baseada no Estado (COHEN; SABEL, 2005). A evolução de organizações internacionais, como a União Europeia (UE) (KJAER, 2010c), a Organização Mundial do Comércio (OMC) e o Banco Mundial, em regimes de elaboração de normas extremamente complexos ilustram que essas estruturas ganharam um nível de autonomia que torna impossível compreendê-las como reflexos puros de uma negociação interestadual. Além disso, o número dessas entidades aumentou drasticamente desde meados do século $X X^{8}$. Mas, além dessa transformação das estruturas públicas interestaduais, surgiram também novas formas de estruturas transnacionais, que não se enquadram nas categorias clássicas de direito e política internacional. Empresas multinacionais (BACKER, 2007), escritórios de advocacia de operação global (THOMPSON, 2006), grupos de reflexão e as principais ONGs estão cada vez mais atuantes como entidades autônomas criadoras de normas fora da estrutura de Estado-nação. Tornaram-se formas autônomas de ordenamento social que constituem seus próprios espaços cognitivos em escala global. Assim, um foco exclusivo em organizações internacionais públicas não será suficiente se alguém procurar descrever a estrutura atual do espaço transnacional.

No entanto, dentro dos estudos acadêmicos, formas públicas e privadas de transnacionalidade estão sendo refletidas em dois discursos separados. Por um lado, a grande maioria dos estudiosos que se afastam do direito público e da ciência política tendem a voltar a atenção para organizações internacionais públicas e questões como o

\footnotetext{
${ }^{8}$ Por exemplo, em 2001, o Anuário das Organizações Internacionais estimou aproximadamente 7.000 organizações intergovernamentais e cerca de 48.000 organizações internacionais privadas. Ver também, www.uia.org/statistics/organisations/11.1.1a.pdf.
} 
surgimento de uma lei administrativa global complexa ${ }^{9}$ ou a questão de como as normas de interação emergem entre os estados. Basicamente, essa linha de pesquisa trata apenas do deslocamento da tomada de decisão pública para longe das esferas dos Estados-nação e para mais perto do domínio transnacional. Assim sendo, essa vertente de pesquisa, permanece essencialmente dedicada à ambição de reformular os conceitos de Estado-nação do direito e da política a fim de torná-los compatíveis com os desenvolvimentos globais em curso. Na maioria dos casos, os pressupostos básicos relativos à forma e à função do direito e do poder político permaneceram inalterados. Por outro lado, um grupo minoritário de acadêmicos, que se distancia principalmente da tradição do direito privado internacional, procura desenvolver conceitos inovadores sobre como a ordem social é produzida no âmbito transnacional por meio de uma tentativa deliberada de estabelecer uma ruptura com a dependência da lei internacional clássica e nos conceitos de relação internacional ${ }^{10}$. Os processos do mundo real que são o foco dos dois grupos diferem de acordo. Como já mencionado, os advogados públicos e os cientistas políticos analisam principalmente o deslocamento do poder público do domínio do Estado-nação para a esfera transnacional. Em contrapartida, estudiosos que se desviam do direito privado tendem a enfatizar fenômenos, como lex mercatória (LIEKWE, 2003) e lex digitalis (KARAVAS, 2007) na estrutura de um programa de pesquisa destinado a conceituar as formas globais de ordenamento social que operam além do domínio público.

No entanto, essa divisão de trabalho é problemática na medida em que o que se observa é o surgimento de uma gama completa de configurações funcionalmente delineadas dentro do espaço transnacional em termos de conglomerados regulatórios em áreas como economia, ciência, meios de comunicação de massa, esportes, meio ambiente e outros. Esses conglomerados caracterizam-se por uma interação altamente complexa entre elementos públicos e privados, em termos de organizações

\footnotetext{
${ }^{9}$ Para uma tipologia de estruturas administrativas globais inspirada em leis públicas de grande utilidade, veja Benedict Kingsbury, Nico Krisch e Richard B Stewart (2005). Para o caso especial da UE, veja Poul F. Kjær (2007). Para uma compreensão do que sustenta as organizações internacionais públicas, veja Jens Steffek (2011).

${ }^{10}$ Veja, por exemplo, Marc Amstutz (2005); Marc Amstutz e Vaios Karavas (2006, 2009); Gunther Teubner e Andreas Fischer-Lescano (2004, 2006).
} 
internacionais públicas e privadas, tribunais internacionais públicos e privados e tribunais judiciais, empresas privadas ${ }^{11}$, grupos de reflexão, organizações não governamentais $^{12}$ etc. Esses conglomerados de ordenamento social não podem, portanto, ser compreendidos de maneira adequada por meio de uma ênfase unidimensional na dimensão pública ou na dimensão privada à custa do outro.

O princípio da desconsideração mútua que parece orientar a relação entre os dois discursos é ainda mais intrigante na medida em que as referências à linguagem constitucional podem ser detectadas em ambos os discursos, assim como seu interesse em pesquisa permanece essencialmente o mesmo na medida em que o objetivo central dos dois discursos é identificar e avaliar normativamente as estruturas constitutivas e limitativas dos processos transnacionais. No entanto, ao fazerem isso, atuam de maneira superficial, uma vez que os conceitos constitucionais a que se referem são marcadamente diferentes. Um grande segmento de advogados privados tende a orientar seus trabalhos para a questão da capacidade do sistema jurídico de enquadrar a dimensão transnacional dos processos sociais relacionados, por exemplo, à economia e à migração, ao mesmo tempo minimizando sistematicamente o aspecto político dos processos em questão ${ }^{13}$. Por outro lado, os estudiosos que partem de uma perspectiva de direito público ou de ciência política tendem a explorar a possibilidade de garantir a primazia do sistema político ou, menos ambiciosamente, investigar o potencial de assegurar a responsabilidade política das estruturas transnacionais (HELD; KOENINGARCHIBUGI, 2005).

Independentemente do nível de ambição, os acadêmicos que partem de uma perspectiva de direito público e ciência política tendem a entender a lei como um instrumento meramente empregado para alcançar objetivos políticos.

O desenvolvimento de uma teoria do constitucionalismo transnacional capaz de estreitar essa lacuna é cada vez mais essencial. Contudo, tal esforço não pode assumir a

\footnotetext{
${ }^{11}$ Veja, por exemplo, Olaf Dilling, Martin Herberg e Gerd Winter (2008); Catá Backer (2007).

${ }^{12}$ Veja, por exemplo, Heike Walk (2004).

${ }^{13}$ É importante enfatizar que este não é o caso de todos os advogados privados. Veja, por exemplo, Christian Joerges e Michelle Everson (2005).
} 
forma de um mero exercício de reconciliação cujo objetivo é obter um compromisso entre as diferentes posições. Ao contrário, o ponto de partida deve ser a percepção de que a lei e a política operam em um ambiente radicalmente diferente dentro do espaço transnacional quando comparado ao contexto do Estado-nação. A função social da lei e da política e, portanto, a posição dos sistemas de direito e política, tanto na sociedade quanto um em relação ao outro, são substancialmente diferentes dentro do espaço transnacional quando comparados ao cenário do Estado-nação. Assim, é fundamental que uma teoria adequada do constitucionalismo transnacional reconfigure a distinção de Estado-nação entre as esferas pública e privada, e também enfatize sistematicamente a transformação coevolucionária da lei e da política em relação à crescente dependência de delineamentos funcionais e setoriais. Mas, sobretudo, tal teoria deve ser construída com base em uma conceituação fundamentalmente diferente. Novos conceitos de direito, política e constitucionalismo adequados ao contexto devem ser desenvolvidos com base em uma teoria geral da sociedade (Gesellschaftstheorie) capaz de descrever as estruturas básicas (Tiefenstrukturen) do espaço transnacional, bem como a relação interligada entre os diferentes polos/camadas da sociedade mundial ${ }^{14}$; uma teoria que, além do mais, deve ser de natureza indutiva, uma vez que deve ser orientada ao problema e ter uma perspectiva focal que a torne capaz de observar como novas formas políticas e legais emergem inerentemente em processos sociais mais amplos. Em outras palavras, tal projeto só poderá ter sucesso se for realizado como projeto sociológico genuíno, uma vez que a sociologia continua sendo a única disciplina capaz de representar o desejo de descrever a estrutura da sociedade em sua totalidade (HABERMAS, 1981, p. 19).

\section{TRANSFORMAÇõES ESTRUTURAIS DA SOCIEDADE MUNDIAL MULTINÍVEL}

A crescente atenção acadêmica dada aos desenvolvimentos transnacionais, nas últimas décadas, pode ser entendida como um reflexo de duas transformações estruturais inter-relacionadas. Primeiro, o polo conhecido como Estado-nação sofreu transformações substanciais desde meados do século XX. O que convencionalmente se entende como

\footnotetext{
${ }^{14}$ Para as múltiplas camadas da sociedade mundial, veja Poul F. Kjaer (2010a); Sassen (2006).
} 
Estado-nação é o resultado de processos de configuração de um século os quais implicavam o surgimento de conglomerados complexos e emaranhados - que, por sua vez, combinavam não só aspectos políticos e legais, mas também, por exemplo, religiosos, econômicos e científicos, organizações, redes e profissões dentro de um segmento limitado da sociedade mundial (KJAER, 2010b). No entanto, o aumento maciço da complexidade interna (Eigenkomplexität) do Estado com o surgimento de disposições de bem-estar cada vez mais complexas ao longo do século XX e a crescente vinculação de segmentos setoriais (SLAUGHTER, 2004) de configurações nacionais e, portanto, delineados por funções com suas contrapartes dentro de outras configurações nacionais, significando que a estabilização mútua entre as diferentes dimensões de configurações nacionais estão cada vez mais tensas; um desenvolvimento que subsequentemente teve efeitos (in)diretos substanciais na camada transnacional. Em segundo lugar, a própria camada transnacional passou por transformações substanciais, que também tiveram consequências substanciais para a camada do Estado-nação. Estamos, em outras palavras, lidando com um desenvolvimento dialético entre camadas mutuamente constitutivas.

Em relação à camada/ao nível do Estado-nação (KJÆER, 2009a), vale a pena observar que, até meados do século XX, a forma moderna de Estado só tinha se materializado em uma parte relativamente pequena do mundo. Somente após a descolonização, o Estado tornou-se um verdadeiro fenômeno global. Foi só então que o globo, na sua totalidade, dividiu-se em estados independentes (STICHWEH, 2007, p. 27). Considerando que o Estado moderno emergiu por meio de uma metamorfose de estruturas feudais já existentes na Europa, que subsequentemente levaram a uma marginalização das mesmas estruturas feudais das quais ele emergiu, o Estado moderno foi imposto externamente através do imperialismo nos cenários (pós-)coloniais. Como consequência, que também é indicada pelas abordagens do pluralismo jurídico, essas grandes partes do mundo, especificamente na África, na Ásia e na América Latina, continuam a ser caracterizadas por uma dualidade entre camadas baseadas no Estado pré-moderno e no Estado moderno (no sentido ocidental), pois formas modernas de organização, essencialmente de origem europeia, tais como sistemas jurídicos codificados e estruturas burocráticas generalizadas, foram impostas "sobre" as formas tradicionais de organização social, sem realmente conseguir 
uma completa marginalização das formas "tradicionais" de organização social. Assim, as diferentes lógicas sociais que elas representam continuam a operar simultaneamente, seja de forma separada, mas emaranhada, ou através da formação de estruturas híbridas que combinam elementos das duas dimensões ${ }^{15}$. As características básicas do Estado moderno e da sociedade, como constituições, direito contratual, direitos de propriedade etc., podem estar em vigor ao mesmo tempo que as formas pré-modernas de diferenciação, para diferentes graus e em variações, e continuam definindo a forma das operações sociais "abaixo" das estruturas formais do Estado, muitas vezes de uma maneira que coloca em atrito as práticas operacionais das estruturas modernas ${ }^{16}$. Os Estados, como Austrália, Canadá e Estados Unidos, nesse sentido, apresentam uma anomalia, pois pertencem ao pequeno grupo de estados com um passado colonial em que as culturas indígenas foram quase completamente erradicadas, tornando a questão de várias camadas uma característica menos distintiva ${ }^{17}$. Assim, é possível observar um desenvolvimento um pouco ambíguo. Por um lado, a maior parte do mundo continua sendo caracterizada por "estados fracos", no sentido em que a soberania em grandes partes do mundo constitui apenas uma camada fina que representa meramente um segmento da sociedade, visto que as formas de ordenamento social que existiam antes do estabelecimento do Estado moderno continuam sendo de vital importância. Por outro lado, o alcance do fenômeno de estado continuou a se expandir rapidamente, não só através da expansão do número de estados como consequência da descolonização, mas também em termos da sua capacidade de reconstruir as estruturas sociais em funcionamento dentro de seus territórios (FOUCAULT, 2007). Por exemplo, as fortes tendências de modernização que podem ser observadas atualmente em relação a estados como Brasil, China e Índia indicam que esses estados também se tornaram gradualmente capazes de marginalizar suas

\footnotetext{
${ }^{15}$ Por exemplo, para o caso do Brasil, veja Leonardo Avritzer (2005); Marcelo Neves (1992).

${ }^{16}$ Conforme destacado por Luhmann, o sul da Itália é um excelente local para observar isto: veja Niklas Luhmann (1995, p. 7-28.). Veja também Kjær (2009, p. 486).

${ }^{17}$ Embora o tamanho dos grupos indígenas que vivem dentro do território destes estados seja tão pequeno que eles dificilmente podem ser entendidos como segmentos constitutivos da sociedade, o modo como a relação entre os segmentos indígenas e não indígenas da sociedade está estruturada pode, contudo, ser entendida ainda como um "caso de teste" para a qualidade normativa das estruturas constitucionais desses estados. Veja, por exemplo, James Tully (1995). Para a interação entre o direito indígena, nacional e transnacional, veja também Christoph Beat Grabher (2009). O sul americano, além disso, apresenta um caso especial; veja, por exemplo, Wolfgang Knöbl (2006).
} 
estruturas de pré-estado.

As transformações estruturais através da expansão do alcance do Estado estão tendo claramente efeitos (in)diretos importantes sobre a camada transnacional da sociedade mundial, uma vez que implicam mudanças no sistema interestadual. Mas, sobretudo, a transformação de uma parte cada vez maior dos estados do mundo em estados modernos significa que eles tendem, em maior medida do que antes, a espelhar a natureza funcionalmente diferenciada da sociedade em sua organização interna, por exemplo, através da diferenciação (Ausdifferenzierung) de um aumento de ministérios, agências e comissões parlamentares funcionalmente delineados, desse modo desfazendo cada vez mais a ilusão de que os estados possuem um centro singular de poder. Os estados estão se tornando "desagregados", que não operam como unidades fechadas. O aumento de desagregação implica que as diferentes dimensões de estados definidas funcionalmente tendem a desempenhar diferentes funções e a perseguir objetivos distintos de uma maneira mais ou menos descoordenada, ao mesmo tempo em que essas dimensões estabelecem relações institucionalizadas tanto para suas contrapartes em outros estados como para estruturas públicas e privadas que operam no espaço transnacional (SLAUGHTER, 2004). Além disso, a expansão da forma moderna de Estado significa que o tipo de diferenciação centro-periferia que até hoje tem sido uma característica central da sociedade mundial, está sendo reduzido lentamente, mas gradualmente. O século XX foi essencialmente uma fase de transição. No início do século, o mundo era constituído com base na distinção entre "Europa e o resto" na qual a Europa poderia ser concebida como um espaço legal específico (Raum) (SCHMITT, 1950). Depois da implosão autoinfligida do espaço europeu, surgiu uma nova distinção entre "o Ocidente e o resto", baseada na hegemonia norte-americana. Mas, no mundo atual, caracterizado pela rápida ascensão de um grande número de estados não ocidentais, a área do Atlântico Norte não constitui mais o centro exclusivo do mundo. Consequentemente, a centralidade relativa da diferenciação centro-periferia está diminuindo.

Uma transformação simultânea ocorreu dentro do próprio espaço transnacional. A expansão do Estado evoluiu de mãos dadas com o surgimento das estruturas transnacionais. Estados europeus (ocidentais) modernos, como Dinamarca, França, Países Baixos, Espanha, Portugal e Reino Unido, surgiram todos através de processos seculares 
que se desdobraram em conjunto com a expansão gradual da transnacionalidade na forma colonial. As ordens constitucionais dos Estados-nação sempre fizeram parte, portanto, de estruturas muito maiores e mais complexas de ordenamento social. Assim, o fenômeno do colonialismo (TULLY, 2007) testemunha que a transnacionalidade não é de forma alguma um fenômeno novo, assim como ilustra que a condição de Estado e transnacionalidade têm, historicamente falando, se reforçado mutuamente, já que a camada transnacional parece ser tão constitutiva para os Estados-nação quanto os Estados-nação são constitutivos para a camada transnacional. Assim, o surgimento do Estado moderno não pode ser entendido corretamente sem levar em conta o surgimento simultâneo de estruturas transnacionais abrangentes. Da mesma maneira que os Estados europeus modernos e clássicos modernos emergiram em conjunto com as estruturas coloniais, a expansão do Estado no século XX se desdobrou em combinação com o fortalecimento progressivo de estruturas transnacionais funcionalmente delineadas. Se alguém classificar os 193 estados existentes atualmente de acordo com a influência que eles têm sobre a sociedade global e compará-los com outras estruturas de ordenamento social, como a Fundação Monetária Internacional (FMI), o Comitê Bancário da Basileia formado pelo grupo G-10, o Wal-Mart e a Cruz Vermelha Internacional de acordo com a influência deles sobre a sociedade global, as últimas entidades provavelmente parecerão mais poderosas do que muitas e, em alguns casos, até do que a maioria dos Estados atualmente existentes (BRAITHWAITE; DRAHOS, 2000, p. 488; NICKEL, 2006).

Neste contexto, o nível de mudança da camada transnacional da sociedade mundial desde meados do século XX torna-se um pouco mais claro. A transformação fundamental ocorrida é que as estruturas transnacionais gradualmente se afastaram da diferenciação centro-periferia ${ }^{18}$ para uma confiança cada vez maior na diferenciação funcional, pois a forma colonial de transnacionalidade centro-periferia foi gradualmente substituída por uma dependência crescente de formas funcionalmente diferenciadas. Atualmente, os assuntos marítimos são tratados pela Organização Marítima Internacional (OMI), a segurança aérea pela Organização da Aviação Civil Internacional (OACl), o setor bancário

\footnotetext{
${ }^{18}$ Para uma tentativa de manter a diferenciação centro-periferia como categoria central, veja o trabalho de Wallerstein; por exemplo, Immanuel Wallerstein (2004).
} 
pelo Comitê da Basileia formado pelo grupo G-10, as normas alimentares pela Organização das Nações Unidas para Agricultura e Alimentação (FAO), o comércio internacional pela OMC e assim por diante. Delineação funcional de formulários semelhantes pode ser observada em relação a organizações reguladoras (semi) privadas, como ISO e ICANN. Além disso, no outro extremo do continuum público/privado, as empresas multinacionais, na sua capacidade de sistemas organizacionais funcionalmente delineados que operam dentro da esfera econômica, emergiram como estruturas autônomas por direito próprio (BACKER, 2007).

Uma característica comum das organizações públicas e privadas que operam no espaço transnacional é que elas, apesar das numerosas previsões em contrário, tendem internamente a ter um núcleo vertical na forma de uma estrutura organizacional hierárquica do tipo originalmente descrito por Weber (1946). A capacidade de impor sanções negativas continua sendo uma característica determinante da configuração interna dessas organizações, embora em graus variados. As empresas multinacionais tendem a desenvolver formas sofisticadas de controle e mecanismos de conformidade, como sistemas de auditoria, que são implantados internamente entre as empresas-mães e suas subsidiárias (e, em diferentes graus, também externamente em relação às cadeias de suprimentos) ${ }^{19}$. Estruturas semelhantes podem ser detectadas dentro das principais ONGs que operam globalmente e em organizações públicas internacionais ${ }^{20}$.

Além disso, uma característica comum tanto das organizações públicas quanto das privadas que operam no espaço transnacional é que elas devem ser entendidas como estruturas autônomas criadoras de normas. Elas são sistemas complexos e, como tais, são forçadas a desenvolver princípios gerais capazes de orientar os processos sociais multifacetados que elas reproduzem com base em afirmações explícitas sobre quais tipos de operações são aceitáveis e quais não são (PARSONS, 1971).

Essa necessidade funcional tende a resultar no estabelecimento de critérios que visem orientar a seleção das operações. A consequência disso não resulta apenas em regras e

\footnotetext{
${ }^{19}$ A título de exemplo, para o caso Wal-Mart, ver Catá Backer (2007).

${ }^{20}$ Um claro exemplo de sistema de certificação para concorrência leal no ramo alimentício é operado pela Flo-Cert (http://www.flo-cert.net).
} 
expectativas compartilhadas, mas também em uma hierarquização a fim de solucionar ou restringir conflitos entre diferentes segmentos de normas ${ }^{21}$.

Além disso, é possível observar o surgimento de regimes abrangentes que unem toda uma gama de atores dentro de um dado campo funcionalmente delineado. $\mathrm{O}$ traço comum tanto das organizações reguladoras quanto das multinacionais é que elas tendem a se tornar parte de conglomerados maiores que incluem uma multiplicidade de atores na forma de produtores, consumidores, reguladores e assim por diante, que, por sua vez, tornam-se parte de processos configurativos funcionalmente delineados que convergem as expectativas entre os atores em questão com base em um conjunto (mais ou menos bem desenvolvido) de princípios, normas e regras, tudo isso constituindo uma "ordem superior"22.

Além disso, tais desenvolvimentos implicam o desenvolvimento de fontes independentes de autoridade. Um exemplo-chave é a função do "conhecimento científico" dentro da regulação de risco (por exemplo, dentro da estrutura de Comitologia da UE e do comitê SPS da OMC). Em outros casos, o pilar dos regimes funcionais tende a ser constituído pelo surgimento de instituições especializadas que desenvolvem instrumentos de classificação implantados globalmente. Esse é, por exemplo, o caso em relação aos mercados de capitais, aos esportes ${ }^{23}$, à liberdade (WERRON, 2009) de imprensa ${ }^{24}$ e ao ensino superior ${ }^{25}$. Esses instrumentos de classificação servem como formas por meio das quais as operações dos atores dentro da área em questão são avaliadas, produzindo, assim, um espaço cognitivo global. Ranking e benchmarks são instrumentos usados para estabelecer estruturas fundamentais em relação às quais outros atores dentro da área funcional em questão devem se posicionar ${ }^{26}$. Eles fornecem a base constitutiva para

\footnotetext{
${ }^{21}$ Em relação a empresas privadas, ver, por exemplo, Klaus Dieter Wolf, Annegret Flohr, Lothar Rieth e Sandra Schwindenhammer (2010).

${ }^{22}$ Stephen D. Krasner (1983, p. 1). Para um exemplo prático, veja o Pacto Global das Nações Unidas.

${ }^{23}$ Em relação às agências de classificação, veja Timothy J. Sinclair (2003).

${ }^{24}$ Por exemplo, veja o Índice Global de Liberdade de Imprensa feito pelos Repórteres sem Fronteiras. Disponível em: http://www.rsf.org/index.php?page=rubrique\&id_rubrique=2. Acesso em: 20 out. 2009.

${ }^{25}$ Por exemplo, o Ranking de Xangai disponível em: http://www.arwu.org, e a Times Higher Education. Ranking disponível em: http://www.timeshighereducation.co.uk. Acesso em: 21 out. 2009.

${ }^{26}$ Sobre o papel constitutivo das agências de classificação em relação ao sistema financeiro global, veja Timothy J. Sinclair, "The Problems of Growing up and getting rich: How the truly obscure became very important in global financial market and to us all" (datilografado em arquivo com autor).
} 
universos funcionalmente delineados com alcance global. Em alguns casos, os rankings são, além disso, complementados por instrumentos de certificação, como os desenvolvidos pela ISO (padrões de produtos) e pela FLOCERT (comércio justo de gêneros alimentícios), que, de maneira ainda mais proativa, buscam transformar o modo de operação dos atores dentro de uma determinada área.

Como consequência, uma multiplicidade de formas diferentes de ordens normativas pode ser observada no espaço transnacional. Existe uma desordem altamente complexa da ordem normativa (WALKER, 2008), pois toda uma gama de estruturas que produzem suas próprias formas de normatividade opera e colide como bolas de sinuca no espaço transnacional. Particularmente, os estados de pequeno e médio porte são, portanto, reduzidos a um conjunto de atores entre vários, quando operam transnacionalmente. $\mathrm{A}$ consequência é que sua autonomia de decisão é estruturalmente limitada, pois eles são realmente forçados a buscar convergência com as normas produzidas transnacionalmente (NICOL, 2010). Os exemplos acima destacam o emaranhado tanto da camada nacional quanto da camada transnacional. As estruturas estatais que operam no espaço transnacional são estruturas nacionais que tendem a desenvolver uma dimensão transnacional adicional. Assim sendo, elas operam simultaneamente dentro de uma multiplicidade de contextos. Elas toleram, interna e externamente, diversas constelações de problemas, normas e procedimentos, tornando o desafio de estabelecer a coerência interna entre os diferentes conjuntos de expectativas um desafio central para as organizações modernas de Estado.

O caso dos atores privados é o mesmo. A maioria das empresas multinacionais começaram em um cenário nacional e só se transformaram em empresas globais ao longo do tempo. Assim, a maioria das empresas multinacionais tendem a estar intimamente alinhadas à cultura empresarial e à ordem legal de seu país de origem. Portanto, o WalMart continua sendo uma empresa bastante americana, e a Toyota, uma empresa bem japonesa. Por outro lado, eles estão envolvidos em operações comerciais de escala global. A consequência é que eles encontram diferentes expectativas e normas em contextos distintos. Uma multidimensionalidade semelhante pode ser observada em relação a outras instituições, como universidades, instituições de pesquisa, escritórios de advocacia e 
ONGs, que desenvolvem uma dimensão transnacional. Assim, é comum que as estruturas públicas e privadas sejam nacionais e transnacionais ao mesmo tempo, ressaltando, assim, que a transnacionalidade deve ser considerada como uma prática social específica por meio da qual emergem normas específicas (WIENER, 2008). Assim, conforme também destacado por Saskia Sassen (2006), as estruturas nacionais e transnacionais representam lógicas diferentes, apesar de não operarem de maneira separada. Em vez disso, elas estão profundamente enredadas e entrelaçadas. Atualmente, todas as cidades europeias de média dimensão mantêm um escritório de representação em Bruxelas, e todas as universidades participam de acordos de cooperação transnacional, e assim por diante. De fato, todas as organizações formais de um certo tamanho tendem a operar em múltiplos $\operatorname{contextos}^{27}$.

Devido ao aumento do estabelecimento de espaços cognitivos funcionalmente delineados, a importância relativa das dimensões transnacionais está, no entanto, aumentando. Por exemplo, as universidades medem cada vez mais o seu grau de sucesso em relação ao desempenho das universidades que operam em outros ambientes nacionais, em vez de se medirem com base na contribuição que oferecem ao próprio ambiente nacional $^{28}$. Assim, é comum às organizações que desenvolvem uma dimensão transnacional descobrir que algumas das atividades nas quais elas estão envolvidas podem ser efetivamente controladas por estados capazes de impor restrições legais ao mesmo tempo que elas, as organizações, pelo menos parcialmente, são capazes de escapar do controle nacional ao operarem em uma capacidade transnacional.

Além disso, uma variação dessa dualidade pode ser observada em relação às organizações internacionais públicas. Elas são organizações internacionais e normalmente são fundadas e financiadas pelos estados. Uma característica central dessas organizações

\footnotetext{
${ }^{27}$ Como destacado por Inger-Johanne Sand em seu comentário, os fundos soberanos são outro excelente exemplo, ao mesmo tempo em que enfrentam a necessidade de atender às expectativas que emergem da política nacional que os iniciou, dos estados em que investem, dos mercados financeiros globais, das organizações internacionais e dos regimes que regulam as áreas nas quais investem e de ONGs que operam globalmente e que insistem em que, por exemplo, preocupações sociais, ambientais e de direitos humanos devem ser refletidas em suas políticas de investimento.

28 Rudolf Stichweh: Centre and Periphery in a Global University System, MS disponível em: http://www.unilu.ch/deu/prof._dr._rudolf_stichwehpublikationen_38043.aspx.
} 
é, portanto, que elas dependem das competências delegadas a elas por seus Estadosmembros. Ao mesmo tempo, mas em graus variados, elas tendem a desenvolver uma dimensão transnacional adicional que escapa ao tipo de controle que pode ser assegurado através da delegação. Isso é especialmente evidente em relação à UE, que, na maioria dos casos, é descrita como uma estrutura composta por uma dimensão intergovernamental $e$ supranacional. A primeira dimensão permanece, pelo menos teoricamente, sob o controle dos Estados-membros, enquanto a operação da última ultrapassa o controle exclusivo desses Estados. Mas, até mesmo dentro de organizações internacionais menos desenvolvidas, uma dimensão transnacional adicional tende a emergir. Por exemplo, a OMC, dentro de um período muito curto, desenvolveu uma dimensão transnacional adicional orientada por uma lógica independente que não pode ser capturada exclusivamente pelo conceito de intergovernabilidade, uma vez que produz regras de ordenação que não podem ser diretamente relacionadas aos seus Estados-membro. Além disso, as organizações internacionais devem ser entendidas como ordens normativas autônomas, que dependem internamente de um núcleo hierárquico, embora muitas vezes muito fraco. Embora incorporem lógicas fundamentalmente diferentes e produzam resultados distintos, as estruturas nacionais e transnacionais compartilham algo fundamental, na medida em que ambas as dimensões dependem da hierarquia legal e organizacional.

\section{LEI E POLÍTICA NAS CONFIGURAÇÕES NACIONAIS}

Outra característica comum das entidades transnacionais públicas e privadas é que elas são entidades criadoras de ordens e, como tais, produzem equivalentes orientadores ou funcionais para governar. Essa percepção torna essencial descobrir a qualidade legal e política específica dessas estruturas, bem como a forma de ordem constitucional que elas produzem quando comparadas com as ordens que caracterizam as configurações do Estado-nação.

O eixo central em que se baseiam os Estados-nação é a maneira específica pela qual os sistemas políticos e legais se orientam uns na direção dos outros. Para Habermas, isso leva a uma conceituação de uma "conexão interna entre direito e poder político". A estabilização das expectativas normativas da lei e a formação da vontade política são vistas como emergentes 
em uma condição de simultaneidade e, deste modo, de uma maneira que garanta uma ordem social legítima e justa (HABERMAS, 1992, p. 167). Para Luhmann (1993, p. 153), a ligação interna entre lei e poder é substituída por uma "certa síntese funcional entre política e lei". Ao contrário de Habermas, Luhmann enfatiza a diferença entre as duas dimensões. Ele destaca que a síntese surge com base em duas funções diferentes: a estabilização das expectativas normativas pelo sistema jurídico e por tomadas de decisão coletivamente vinculantes por parte do sistema político. No entanto, a diferença entre as duas posições é mais gradual do que fundamental, uma vez que a transferência dos componentes de significado de uma esfera para a outra é abordada de uma perspectiva processual por ambos os estudiosos. Além disso, Luhmann também reconhece que é provável que a síntese funcional garanta certas "sobreposições" nos modos de autodescrição tanto do sistema jurídico quanto do sistema político em relação a conceitos, como legitimidade e justiça (LUHMANN, 1997). Assim, é de fato possível alternar entre as duas posições (TEUBNER, 1982).

O principal problema enfrentado pelos complexos teóricos de Habermas, em particular, mas também de Luhmann, deve ser encontrado em outro lugar. O problema é que eles presumem (Habermas) ou descrevem (Luhmann) uma ordem hierárquica, pois veem os sistemas político e jurídico como caracterizados pela hierarquia organizacional Weberiana e legal Kelsiana. Embora Luhmann, desde cedo, expressasse seu ceticismo sobre a viabilidade futura dessas estruturas (LUHMANN, [1972] 1983, p. 339), suas descrições da sociedade moderna, no entanto, mantêm uma forte visão de Estado-nação. Isso pode parecer paradoxal quando se considera sua tônica em uma única sociedade mundial (LUHMANN, 1971; LUHMANN, 1997, p. 145). Especialmente em relação aos sistemas jurídico e político, o conceito de sociedade mundial é, no entanto, menos radical do que parece, na medida em que o foco central de Luhmann continua sendo sobre estruturas hierárquicas legais e organizacionais que estão se desdobrando dentro de subsistemas territorialmente delineados. Assim, a maior parte das suas descrições das operações dos sistemas político e jurídico continuam se referindo às estruturas hierárquicas de Estado-nação ${ }^{29}$.

\footnotetext{
${ }^{29}$ Por exemplo, suas duas principais obras sobre lei e política, Recht der Gesellschaft (Frankfurt aM, Suhrkamp Verlag, 1993) e Politik der Gesellschaft, (Frankfurt aM, Suhrkamp Verlag, 2000), lidam quase que completamente com a lei e a
} 
Além disso, a tentativa de justificar a alegação de que a soma de um único subsistema social é maior do que a soma da sociedade como um todo levou Luhmann a ignorar os aspectos configurativos da sociedade. Os subsistemas jurídico e político, delineados a nível nacional, também estão dentro das partes de configurações maiores da camada de Estado-nação. Essas configurações consistem em uma densa teia de associações estruturais que se reforçam política, bem como sistemas como economia, educação, ciência, saúde, esportes etc. Esses subsistemas não são necessariamente delineados ao longo de linhas territoriais completamente idênticas ${ }^{30}$, mas, na maioria dos casos, são caracterizados por fortes sobreposições entre as delimitações territoriais a que se referem. Além disso, é possível observar uma "variedade mutuamente e se sobrepõem parcialmente entre os subsistemas funcionais de direito e de configurações", uma vez que existem diferenças substanciais entre as configurações existentes, indicando que elas estão produzindo um valor adicional que torna necessário defini-las como fenômenos sociais independentes.

As configurações nacionais podem, além disso, ser descritas como "sociedades organizacionais" (Organisationsgesellschaften). Foram as revoluções organizacionais dos séculos XVII e XVIII que forneceram a base para as revoluções política e econômica que são normalmente consideradas como as forças motrizes por trás do estabelecimento das configurações de Estado-nação (HARSTE, 1997). Assim, uma forte dependência dos sistemas organizacionais é, em muitos aspectos, a característica mais profunda das configurações nacionais, no sentido de que os subsistemas funcionais delineados territorialmente navegam em um mar de organizações. A força integradora (Zusammenhangskraft) das configurações é, portanto, estabelecida principalmente no nível organizacional, uma vez que toda uma gama de organizações, de tribunais constitucionais e bancos centrais a universidades, serve como associações estruturais entre sistemas funcionais. Essas associações são, além disso,

política na forma de Estado-nação. Para outros sistemas, de acordo com os estudiosos teóricos, como Marc Amstutz e Gunther Teubner, isso é diferente.

${ }^{30}$ Um exemplo em relação ao sistema econômico, em que esse não é o caso, é a união monetária entre Bélgica e Luxemburgo antes da adoção do euro. A ciência social e humanista alemã e o regime de ensino superior, além disso, parecem ser delineados ao longo de linhas linguísticas, em vez de territoriais, no sentido de que a Áustria e as partes da Suíça de língua alemã também estão incluídas. Além disso, dentro da área de esportes, é possível observar que os clubes de beisebol canadenses jogam na Liga dos EUA. Para reflexões mais gerais, veja também: Poul F. Kjaer (2011). 
complementadas por toda uma série de regimes, que vão desde estruturas de mercado de trabalho corporativista nacionalmente delineadas até ligas nacionais de futebol, que não podem ser incluídas nas categorias de sistemas organizacionais ou funcionais ${ }^{31}$.

A interação complexa entre toda uma gama de estruturas organizacionais nas quais dependem as configurações nacionais dificilmente surpreende que as estruturas constitucionais sempre existiram fora do domínio do Estado. Não apenas sistemas funcionais e organizacionais não estatais, mas também regimes que foram continuamente estabilizados constitutivamente e restritivamente através da lei na camada de Estado-nação da sociedade mundial como a existência de uma multiplicidade de, por exemplo, constituições da igreja, constituições econômicas e trabalhistas e constituições de empresa são testemunhas.

De uma perspectiva hegeliana, essas estruturas podem, é claro, ser entendidas também como parte do Estado, na medida em que Hegel introduziu um conceito tridimensional do Estado ${ }^{32}$. Em primeiro lugar, ele entendia o Estado como composto dos sistemas jurídico e político no "sentido restrito", isto é, de estruturas funcionalmente delineadas, como o governo, a burocracia estatal e os tribunais. Em segundo lugar, ele entendeu o Estado como uma entidade que compõe a sociedade como um todo. Nesse entendimento do Estado, os regimes de mercado de trabalho corporativista, por exemplo, podem ser entendidos como parte do "Estado maior". Em terceiro lugar, ele entendeu o Estado como um recipiente que se constitui através do delineamento de um estado para outros estados. Conceitualmente, no entanto, esse conceito tridimensional sofre de falhas óbvias porque continua confusa a relação entre as três formas do Estado, e como a unidade das três formas é constituída. Além disso, a aceleração do afastamento estrutural das configurações nacionais e em direção a configurações globais nos últimos cinquenta anos tornou a teoria empiricamente ultrapassada ${ }^{33}$.

Luhmann, por outro lado, reduziu essencialmente o Estado à primeira dimensão de

\footnotetext{
${ }^{31}$ Luhmann desenvolveu uma teoria elaborada das organizações. Veja, em particular, Niklas Luhmann (2000a). O problema é o status limitado que ele concede aos sistemas organizacionais em face aos sistemas funcionais dentro da sociedade. Por exemplo, um aviso de que os sistemas organizacionais ocupam apenas 21 páginas de sua teoria geral da sociedade de 1.164 páginas. Veja Luhmann (1997, p. 826-847).

${ }^{32}$ Neil Walker usa o termo "Estrutura keynesiana-westfaliana" para descrever o que é essencialmente idêntico à constelação de estado e sociedade descrita por Hegel. Veja Georg W. F. Hegel [1821] 1970); Neil Walker (2008).

${ }^{33}$ Para investigações empíricas sobre a transformação do estado, veja Stephan Leibfried e Michael Zürn (2005).
} 
Hegel, com base na ideia de que existem fronteiras claras entre o sistema político e outras esferas da sociedade (LUHMANN, 2000b). Essa posição, no entanto, só é possível porque ele reduziu a política a um fenômeno que se desdobra meramente no meio do poder, que é novamente caracterizado pela capacidade de impor sanções negativas formalizadas ${ }^{34}$. No entanto, essa posição tanto é conceitual quanto empiricamente problemática. A redução do poder à capacidade de implantar sanções negativas formalizadas depende, essencialmente, de um antigo conceito de poder europeu (Alteuropäische) e da ideia de que o poder pode estar claramente localizado dentro de estruturas institucionais específicas (BORCH, 2005). Empiricamente, a acentuada distinção que ele introduz entre poder e influência, sendo esse último caracterizado pela ausência da capacidade de implantar sanções negativas formalizadas, tem sido um elemento de definição da sociedade. Em vez das distinções maniqueístas de Luhmann, a sociedade é, em vez disso, caracterizada por um contínuo que representa diferentes tons de cinza, nos quais a fronteira entre poder e influência não está bem definido ${ }^{35}$. Por exemplo, estruturas (neo) corporativistas servem, ou serviram, como regimes que asseguram, ou asseguraram, a inserção do sistema político na forma de Estadonação na sociedade mais ampla que estabeleceu laços institucionalizados entre os domínios político e econômico. Da mesma forma, as estruturas de governança hoje garantem a inserção do sistema político da União Europeia (UE) na sociedade em geral (KJÆER, 2009a). A existência desses regimes torna o sistema político um fenômeno gradual ou concêntrico, que se torna mais denso quanto mais você se aproxima do núcleo do sistema e mais poroso quanto mais distante da periferia você estiver. Assim, a supremacia da racionalidade política torna-se gradualmente mais fraca quanto mais se avança para a periferia. Por exemplo, enquanto a racionalidade econômica está claramente subordinada à supremacia da política quando os estados aplicam a política fiscal, o elemento político, embora ainda presente, torna-se subordinado à racionalidade econômica dentro da esfera do lobby corporativo. Esses casos claros de supremacia, no entanto, são raros. Na prática, as formas políticas e não

\footnotetext{
${ }^{34}$ Em contraste com o recente Luhmann, o Luhmann anterior reconheceu especificamente a existência do poder da sociedade. Veja Niklas Luhmann ([1975] 1988, p. 88).

${ }^{35}$ Por exemplo, o Método Aberto de Coordenação no contexto do processo de integração europeu e seus predecessores dentro da OECD não são capazes de invocar sanções negativas, mas estão, no entanto, produzindo poder. Veja Poul F. Kjær (2008, p. 31).
} 
políticas de racionalidade, deslizam umas sobre as outras de uma maneira impalpável, alimentando, assim, a incerteza sistemática. Não é de admirar que a relação entre racionalidade política e racionalidades não políticas tenha, portanto, conduzido a uma contínua batalha de supremacia no que se refere aos delineamentos apropriados da esfera política $^{36}$.

Assim, as configurações nacionais não estão totalizando as entidades políticas no sentido hegeliano, nas quais a sociedade em sua totalidade é integrada sob a racionalidade do sistema político dentro da estrutura do Estado. Por outro lado, elas não são entidades puramente metafóricas que apenas refletem a semântica instrumental do sistema político, como argumentado por Luhmann. Em vez disso, somos confrontados com a necessidade de desenvolver um conceito coerente da esfera política que reconheça que as formas políticas de comunicação estão presentes em toda a sociedade, embora de modos diferentes e com intensidade distinta.

Isso também é aparente em relação aos tipos de estruturas constitucionais que surgiram na sociedade em geral ao longo da era do Estado-nação. Os Estados-nação eram apenas parcialmente bem sucedidos em sua tentativa de erradicar as formas anteriores de constitucionalismo feudal $^{37}$, mas, são entendidos como uma estrutura jurídica que estabiliza as estruturas não jurídicas ao longo do tempo por meio da reprodução de regras constitutivas e limitativas. Toda uma série de estruturas constitucionais pode, como já mencionado, ser observada, por exemplo, na forma de constituições econômicas, constituições trabalhistas, constituições de mídia e constituições da igreja. Essas constituições são, em alguns casos, orientadas para sistemas funcionais como tais. Em outros casos, elas são orientadas para regimes específicos ou meramente para organizações. Algumas dessas constituições estão intimamente ligadas ao sistema político. Elas são estabelecidas por iniciativa do sistema político ou, pelo menos, estão sujeitas à supervisão política, ao passo que, em outros casos, elas emergem de maneira autônoma e evitam a tentativa do Estado de exercer controle. Mas, além dos elementos derivados do

\footnotetext{
${ }^{36}$ Veja, por exemplo, Karl-Heinz Ladeur (2006).

${ }^{37}$ Para uma crítica inicial do impacto contínuo das estruturas feudais no contexto alemão, veja Georg W. F. Hegel ([1800-02] 1971).
} 
sistema específico em questão, todos eles implicam um elemento jurídico, e também político, permitindo entender a síntese funcional do direito e da política como o eixo central ou o núcleo em torno do qual as configurações nacionais são organizadas ${ }^{38}$.

\section{METAMORFOSE CONSTITUCIONAL}

A natureza distinta dos espaços nacional e transnacional é também aparente em relação ao fenômeno específico do constitucionalismo. Apesar das grandes e importantes diferenças na função e na forma das estruturas transnacionais, uma característica aparentemente comum das estruturas globais é que a "síntese funcional" entre lei e política é ainda mais fraca, se é que existe, quando comparada ao cenário de Estado-nação. Regimes jurídicos transnacionais muitas vezes se baseiam em "leis feitas por juízes" em uma extensão muito maior do que no caso das estruturas de Estado-nação já que as normas legais são desenvolvidas sem referência (ou somente com pouca referência) à legislação formal produzida dentro do sistema político. Além disso, como destacado pelo surgimento dos modos Quase-direito ("soft law"), as estruturas político-administrativas transnacionais expandem suas operações com frequência sem depender de uma base legal formal. Se ela ocorrer, a lei é principalmente ativada ex-post a fim de formalizar as estruturas já existentes (LADEUR, 1997). Na sua organização interna, as estruturas político-administrativas transnacionais são, além disso, caracterizadas por uma ausência de democracia, uma vez que nenhuma delas opera com base na hierarquia "com um pico dividido" através da institucionalização da distinção e da contínua oscilação entre governo e oposição (LUHMANN, 1994, p. 127), ou de uma maneira que corresponda aos conceitos mais tradicionais da democracia parlamentar (NEYER, 2008). O que estamos testemunhando é um desenvolvimento evolutivo no qual a tentativa de canalizar os fluxos de comunicação para procedimentos democráticos tornou-se cada vez mais marginalizada, pois tais procedimentos não são complexos e flexíveis o suficiente para lidar com os enormes aumentos na complexidade social que caracterizam a modernidade radical. Além disso, a

\footnotetext{
${ }^{38} \mathrm{Na}$ verdade, Luhmann também reconhece que o eixo entre lei e política, em termos de função social, gozam de uma posição privilegiada na medida em que o complexo político-jurídico promove a compatibilidade das estruturas de tempo da sociedade na sua totalidade ("gesamtgesellschaftlichen Zeitausgleichs"). Veja Niklas Luhmann (1993, p. 429).
} 
limitação territorial, estabelecida por meio da referência à metáfora das pessoas nas formas democráticas de comunicação, tornou-se um obstáculo para a solução adequada de problemas em um mundo global. Portanto, a síntese funcional entre direito e política (democrática) parece não existir dentro do espaço transnacional (AMSTUTZ; KARAVAS, 2006).

Assim, o sistema jurídico foi forçado a estabelecer "parcerias" diretas, assumindo a forma de constituições sociais funcionalmente delineadas, com outros sistemas funcionais. Por exemplo, as constituições socioeconômicas, que constituíam uma característica importante das configurações nacionais (europeias) foram, de certa forma, marginalizadas devido ao surgimento de novas constituições econômicas funcionalmente delineadas, como aconteceu na estrutura da Comunidade Europeia nos primeiros dias ${ }^{39}$, e ainda é o caso com o regime atual da OMC. No entanto, esses regimes representam uma visão econômica muito mais estreita do mundo, quando comparados com a perspectiva socioeconômica mais ampla que caracteriza o fenômeno do corporativismo do Estado-nação. Assim, as constituições econômicas foram complementadas por toda uma série de constituições funcionais na forma de, por exemplo, uma constituição digital global, uma constituição de saúde global, uma constituição esportiva global e assim por diante (TEUBNER, 2003). Essas constituições são não estatais centradas e espontâneas, agindo como associações estruturais complexas entre o sistema jurídico e sistemas funcionais específicos. Essas constituições fornecem uma base para a estabilização dos sistemas em questão através de meios legais, bem como para o estabelecimento de mecanismos reflexivos capazes de assegurar que elas exerçam autodomínio, de modo a reduzir as externalidades negativas, as assimetrias e os efeitos de "crowding-out" face a outros sistemas. Como tal, elas combatem as consequências das capacidades reduzidas de absorção dos procedimentos democráticos.

\section{REINTRODUZINDO A POLÍTICA}

A metamorfose da síntese funcional e o surgimento de toda uma série de parcerias constitucionais entre o sistema jurídico e os vários sistemas funcionais coloca a questão de

\footnotetext{
${ }^{39}$ Veja, por exemplo, Ernst-Joachim Mestmäcker (2003).
} 
quais estruturas institucionais e condições pré-legais precisam estar em vigor dentro dos sistemas não legais para que atuem como parceiras adequadas ao sistema jurídico. Enquanto o trabalho existente no constitucionalismo social (global) aparentemente assume que essas estruturas estão em vigor, é possível argumentar que isso não pode ser simplesmente assumido. A alegação de que tais estruturas existem deveria ser resultante de observações empíricas feitas com base em uma estrutura conceitual que possibilita a observação dessas estruturas.

A hipótese que será defendida aqui é que a condição que precisa estar em vigor para que sistemas específicos sejam capazes de se engajar em associações estruturais que possuam uma qualidade constitucional com o sistema jurídico é a existência inerente de estruturas reguladoras que produzem equivalentes funcionais para a tomada de decisões políticas na forma de Estado-nação, e não apenas na maneira direta entre a lei e um determinado sistema focal, como argumentado por Teubner. Somente quando tais estruturas existem é possível a ramificação normativa através da constitucionalização. Assim, as associações constitucionais não ocorrem antes entre a lei e um sistema específico como tal, mas, ao contrário, entre a lei e as estruturas reguladoras com uma qualidade política distinta que emerge inerentemente nos sistemas focais (HOLZER, 2006). Em relação aos 125 tribunais transnacionais e às estruturas judiciais que operam atualmente $^{40}$, a suposição que será seguida é, portanto, de que a grande maioria dessas estruturas tem uma contrapartida política. Por exemplo, o Tribunal Arbitral do Esporte desenvolve normas jurídicas com base em referências aos processos essencialmente políticos envolvendo o Comitê Olímpico Internacional. No caso da OMC, o Órgão de Solução de Controvérsias está inserido na estrutura decisória mais ampla da OMC. Assim, a síntese funcional entre lei e política pode não ter desaparecido totalmente. Em vez disso, ela acaba de passar por uma metamorfose que é, no entanto, imperceptível, desde que permaneça comprometida com um conceito da política que foi desenvolvido dentro do contexto do Estado-nação.

Portanto, o aumento da significância das estruturas transnacionais em relação às

\footnotetext{
${ }^{40}$ De acordo com o projeto sobre tribunais e tribunais internacionais. Para obter mais informações, veja http://www.pict-pcti.org.
} 
estruturas do Estado-nação não deve ser necessariamente entendido como implicando uma despolitização, mas simplesmente exige uma reavaliação das diferentes dimensões do conceito de política. O desafio consiste em desenvolver tanto um conceito da política que é libertada do nacionalismo metodológico (ZÜRN, 2001), quanto o pensamento holístico que permitirá a observação da nova forma de política que está se desdobrando dentro das estruturas transnacionais.

Uma teoria exaustiva de constitucionalismo social global deveria ser, portanto, uma teoria bidimensional, na medida em que as perspectivas jurídicas já existentes, como as desenvolvidas, por exemplo, por Amstutz, Joerges, Koskenniemi e Teubner, deveriam ser complementadas por uma teoria correspondente dos processos políticos conforme elas se desdobram dentro ou em relação a cada sistema funcional. Para a definição anterior de estruturas constitucionais, como as estruturas jurídicas que asseguram um enquadramento constitutivo e limitativo dos processos sociais ao longo do tempo, devese, em outras palavras, acrescentar que a condição estrutural para o surgimento desses processos é que eles desenvolvam formas institucionais capazes de reproduzir formas políticas de comunicação, e que o desenvolvimento inerente de estruturas jurídicas e políticas provavelmente evoluirá de uma forma coevolucionária sem que nenhum dos dois elementos sirva como a dimensão principal.

Os processos políticos transnacionais são processos funcionalmente delineados que se desdobram dentro dos limites das configurações globais. É possível observar três dimensões, que servem como equivalentes funcionais do conceito tridimensional de Hegel da política dentro da estrutura de estados territoriais: 1) Processos políticos que se desdobram através de tomadas de decisão coletivamente vinculantes. Por exemplo, dentro da esfera econômica, organizações internacionais públicas, como a OMC e o FMI, agem como instituições genuinamente políticas que produzem decisões coletivamente vinculantes, ao mesmo tempo em que são principalmente guiadas pela racionalidade política e apenas secundariamente pela racionalidade econômica. Como tal, elas servem como equivalentes funcionais, que são funcionalmente, em vez de territorialmente, delineados, da primeira das três dimensões de Hegel do Estado. 2) Processos baseados em regime que agrupam uma variedade de elementos $e$ atores públicos e privados operando 
dentro de um determinado sistema ou esfera funcional. Por exemplo, na forma das cadeias de suprimento e de produção complexas das quais dependem as empresas multinacionais, por meio de associações comerciais de operação global, formas privadas de autorregulação e de produção de normas, como programas de certificação e organismos privados de normalização etc. Aqui, a racionalidade do sistema em questão, como o sistema econômico, provavelmente é o ponto de apoio ao mesmo tempo em que o sistema assume uma qualidade política secundária, na medida em que as ordens sociais que elas constituem permanecem contestadas. 3) Com o surgimento de estruturas voltadas para o tratamento de externalidades negativas, efeitos de "crowding out" e assimetrias (por exemplo, na forma de corrupção e poluição) entre esferas funcionalmente diferenciadas, por exemplo, medidas de Responsabilidade Social Corporativa (RSC), estruturas reguladoras de riscos públicas e privadas e parcerias entre, por exemplo, firmas, ONGs e instituições de pesquisa. Essas estruturas "intermediárias" tendem a agir como "terras sem dono", na qual diferentes ordens normativas entram em conflito porque diferentes esferas de significado (Sinnwelten) estão em conflito.

Além disso, é possível observar que as estruturas transnacionais adotaram uma série de conceitos que servem como os equivalentes funcionais dos conceitos que fornecem a infraestrutura constitutiva da política na forma de Estado-nação. Os conceitos de "nação", "esfera pública", "representação" e "delegação" estão sendo substituídos pelos conceitos de "stakeholders", "transparência", "autorrepresentação" e "responsabilidade". Como será evidente a seguir, os conceitos transnacionais têm um componente cognitivo muito mais elevado do que suas contrapartes de Estado-nação, ilustrando, assim, que não apenas o direito transnacional, mas também a política transnacional são caracterizados por um alto grau de cognitivização.

No que diz respeito às partes interessadas, o meio do sistema político na forma de Estado-nação é a nação (ou "o povo"), entendida como uma construção generalizada e abstrata conscientemente desenvolvida por subsistemas delineados territorialmente do sistema político global a fim de: 1) delinear o alcance de seu poder; 2) agir como uma forma pela qual o poder é transposto para outras partes da sociedade e 3) como uma forma pela qual a complexidade social é reduzida, porque o conceito de nação é usado 
para delinear a parte do mundo que um determinado subsistema político considera em sua tomada de decisão. A última forma está intimamente associada ao conceito de democracia, pois a democracia pode ser entendida como uma forma específica através da qual o sistema político observa seu ambiente. Uma forma que é caracterizada por uma dualidade entre estabilidade e mudança, uma vez que o povo, através da concepção de nação, é definido como uma entidade (relativamente) estável, ao mesmo tempo que a "natureza do povo" em termos de preferências, interesses e normas é dinâmica, permitindo, assim, que o sistema político aumente seu nível de reflexividade e, portanto, sua capacidade de adaptação quando ocorrem mudanças em seu ambiente. Assim, a especificidade da democracia (quando comparada a outras formas de governo, como o feudalismo e o totalitarismo) é que, no âmbito da nação, ela permanece aberta ao futuro, ou seja, o que conta como um problema politicamente relevante, ou como ele deve ser tratado, não é prescrito (FOUCAULT, 1997, p. 24; LUHMANN, 1994). Nesse sentido específico, a democracia é caracterizada por um alto nível de adaptabilidade, e essa é provavelmente a razão pela qual ela provou ser "superior evolutivamente" quando comparada com as outras formas de regra que existiram até hoje.

O conceito de stakeholder cumpre essencialmente um papel semelhante no espaço transnacional. As estruturas transnacionais são caracterizadas por uma ausência de políticas territorialmente delineadas. Isso leva à incerteza sistemática sobre o que é o "coletivo" com base no qual a tomada de decisões dentro de estruturas transnacionais é orientada, assim como permanece incerto quem exatamente é afetado por tais decisões e, muito mais incerto, qual segmento das estruturas transnacionais do ambiente social deve ser observado para que seja possível se adaptar às mudanças nos ambientes. O conceito de stakeholders pode ser considerado uma resposta a essa incerteza. Os stakeholders são um conjunto institucionalizado de "atores" aos quais é concedido o status privilegiado de "partes afetadas" e, portanto, eles detêm o direito de "alimentar" os processos de decisão, ao mesmo tempo que também servem como destinatários dessas decisões. Assim, o status de stakeholder serve como uma forma pela qual a entidade em questão delineia a seção de seu ambiente social que considera relevante à sua operacionalidade. É a forma pela qual ele transmite os componentes significativos (como atos jurídicos, produtos industriais 
ou decisões políticas) que reproduz ao mesmo tempo em que serve como uma estrutura por meio da qual as mudanças no ambiente social podem ser observadas fornecendo, assim, uma base para uma maior adaptabilidade através do aumento da reflexividade. A partir de uma perspectiva histórica, as nações raramente foram estáveis em termos de extensão e composição. A forma do stakeholder é, no entanto, ainda mais "fluida". As dinâmicas de inclusão e de exclusão operam com uma velocidade muito maior em relação aos stakeholders. As fronteiras dos regimes de stakeholder são, nesse sentido, extremamente contingentes. Essa flexibilidade, por um lado, torna-os mais adaptáveis do que a forma da nação e, portanto, potencialmente mais "superiores evolutivamente" do que as estruturas democráticas. Por outro lado, o preço pago por essa fluidez é uma "perda de profundidade" já que o tipo de impacto que pode ser alcançado com essa forma pode ser relativamente limitado, pois ela pode ser descartada como uma mera forma de "conversa barata" com pouco ou nenhum impacto substancial.

\section{TRANSPARÊNCIA}

A esfera pública, no contexto de Estado-nação, é amplamente entendida como a forma pela qual ocorre a formação da vontade da política (HABERMAS, [1962] 1990). No entanto, aumentos radicais na complexidade social indicam que apenas um número muito limitado de questões potencialmente relevantes pode ser processado dentro da esfera pública. Embora o sistema de mídia de massa, que serve como um componente central da esfera pública, tenha sofrido uma profunda globalização em décadas recentes, a esfera pública permanece essencialmente limitada à forma de Estado-nação ${ }^{41}$. No espaço transnacional, por outro lado, organizações, como firmas multinacionais, organizações internacionais públicas e privadas e outros organismos transnacionais, com base em processos autorreflexivos, desenvolveram princípios e políticas de transparência que visam aumentar sua observabilidade por outras estruturas. Essas estruturas incluem, por exemplo, regras que determinam o acesso a documentos dentro de organizações públicas internacionais e as medidas tomadas para o desenvolvimento de um regime global de

\footnotetext{
${ }^{41}$ Embora para o contexto europeu, veja Klaus Eder (2000); Klaus Eder e Hans J. Trenz (2004).
} 
padrões de contabilidade financeira. Além disso, em relação a esse aspecto, esse desenvolvimento implica uma maior confiança nas estruturas cognitivas, pois as estratégias de transparência permitem que outras entidades sociais observem os desenvolvimentos dentro da entidade social em questão e se adaptem de modo adequado, sem necessariamente se engajar na difícil tarefa de formação de vontade comum.

\section{AUTORREPRESENTAÇÃO}

Dentro da filosofia continental, a noção de representação foi desconstruída há muito tempo (BRUNKHORST, 2010).

No entanto, dentro da teoria jurídica e política, bem como em relação à autocompreensão e ao estabelecimento institucional das democracias de Estado-nação, o conceito continua a desempenhar um papel central. Na ausência de estruturas representativas do tipo que caracterizam as democracias, as entidades que operam no espaço transnacional foram forçadas a desenvolver estratégias de autorrepresentação com base na racionalidade dramatúrgica, para usar um termo habermasiano. As estruturas transnacionais se reapresentam em seus ambientes, criando ativamente uma imagem de si mesmas para seus ambientes para observação (sendo, assim, diferentes da forma passiva de observabilidade descrita acima). As organizações públicas desenvolvem programas de políticas e estabelecem metas para sua realização, assim como as multinacionais e as ONGs desenvolvem códigos de ética sobre o modo como conduzem suas atividades. Elas declaram publicamente suas intenções na forma de atos ilocucionários que tendem a se tornar (mais ou menos) autovinculativos ${ }^{42}$, pois, de outra forma, ficariam presos em contradições performativas que poderiam ser apreendidas e utilizadas por grupos "oponentes" (por exemplo, por ONGs em relação a multinacionais).

\section{RESPONSABILIZAÇÃO}

Intimamente relacionado ao conceito de representação, o conceito de delegação desempenha um papel importante na configuração institucional dos estados, bem como

\footnotetext{
${ }^{42}$ Para esta perspectiva, veja, em particular, o trabalho de Martin Herberg: por exemplo, Martin Herberg (2007, 2008).
} 
na sua interação com a camada transnacional devido à delegação de competências a organizações internacionais. Como observado anteriormente, a delegação é, no entanto, sempre mais do que apenas isso. Cada delegação de competências jurídicas implica um reconhecimento de facto da autonomia das estruturas às quais as competências são delegadas. As estruturas que operam com base na delegação tendem a exercer poderes discricionários significativos e a enquadrar as áreas políticas de modo a produzir um número limitado de opções para o desenvolvimento de políticas adicionais. Elas também tendem a desenvolver normas e tornar-se atores políticos por direito próprio (COHEN; SABEL, 2005). A delegação de competências sempre implica um passo ao desconhecido e ao incontrolável. Portanto, existe uma "lacuna" entre o que pode ser controlado através da delegação e as estruturas que estão realmente em vigor. É essa lacuna que está sendo preenchida pelo surgimento de diferentes formas de medidas de responsabilização, por exemplo, por meio do desenvolvimento de cartas de prestação de contas que estabelecem padrões e normas operacionais. Esse desenvolvimento também pode ser visto como intimamente relacionado ao desenvolvimento de um "direito à justificação", uma vez que os atores externos que são (negativamente) afetados por uma determinada atividade, por exemplo, em relação ao efeito da exploração dos recursos naturais em populações locais, tendem a desenvolver alegações de que o efeito deve ser justificado (NEYER, 2008, $2010)^{43}$.

As formas institucionais das diferentes dimensões da forma transnacional da política são radicalmente diferentes das estruturas democráticas na forma do Estado-nação. Se permanecermos comprometidos com a estrutura cognitiva das teorias clássicas de democracia, as formas transnacionais da política não são estruturas não democráticas, mas estruturas ademocráticas por estarem além da democracia. Qualquer conceituação adequada dessas estruturas exigirá, portanto, um movimento conceitual deliberado voltado para "obter a democracia passada" (RUBIN, 2001) ou, pelo menos, a democracia passada nas formas que conhecemos até hoje.

Embora, à primeira vista, produzam efeitos sociais semelhantes aos das estruturas

\footnotetext{
${ }^{43}$ De uma maneira mais geral, veja Rainer Forst (2007).
} 
democráticas, as formas transnacionais da política têm um status e uma posição fundamentalmente diferentes na sociedade quando comparadas à forma de Estado-nação da política. A função social da política no auge da construção do Estado-nação era "levar a sociedade adiante". Ideologias, como liberalismo e socialismo, visavam alcançar a emancipação através de uma ruptura com a tradição. Elas eram motores de mudança social que visavam a acelerar o tempo social através de processos de modernização. Historicamente falando, os universos dos Estados-nação e, com eles, as economias capitalistas modernas eram, portanto, em grande parte, deliberadamente construídas pelo estado (KJ/ER, 2009b). As estruturas transnacionais são, ao contrário, ordens muito mais espontâneas que emergiram de forma incremental como resultado das necessidades funcionais. As dimensões políticas explícitas dessas estruturas tendem a emergir ex post. Nem as multinacionais nem as ONGs estão inclinadas a ter um projeto político explícito como ponto de partida. Em vez disso, elas estão interessadas em explorar as demandas de mercado descobertas e em solucionar problemas sociais concretos. A "consciência política" dessas estruturas tende a emergir à medida que crescem e se tornam estruturas cada vez mais autônomas, produtoras de suas próprias formas de ordem social. Atores que, pela própria existência, são suscetíveis a produzir efeitos substanciais indesejados em relação aos seus ambientes sociais, provocando, assim, a necessidade de institucionalização dos processos destinados a lidar com esses efeitos.

O mesmo é o caso das organizações internacionais. Os predecessores do que é hoje a UE ${ }^{44}$ foram fundados como "comunidades jurídicas" que foram, de muitas maneiras, deliberadamente construídas como entidades tecnocráticas que evitavam a politização de alto nível de suas respectivas áreas funcionais como um objetivo central. Só por ter continuado a expandir seu alcance, a UE foi forçada a desenvolver características políticas autênticas. No mundo transnacional, a busca de objetivos políticos não é a principal razão de ser. Como tal, as formas transnacionais da política tendem a ser uma comunidade política aparentemente impossível de alcançar para as estruturas que operam sem formas compensatórias territoriais bem definidas, que apenas lidam com externalidades negativas

\footnotetext{
${ }^{44}$ A Comunidade Europeia do Carvão e do Aço, a Comunidade Econômica Europeia e a Comunidade Europeia da Energia Atômica.
} 
que ficam muito aquém dos ideais do Estado-nação de uma comunidade política como um fim em si mesmo. Portanto, esse é um tipo de limite.

\section{REFERÊNCIAS}

AMSTUTZ, Marc. In-Between Worlds: Marleasing and the Emergence of Interlegality in Legal Reasoning. European Law Journal, n. 11, p. 766-784, 2005.

AMSTUTZ, Marc; KARAVAS, Vaios. Rechtsmutation: Zu Genese und Evolution des Rechts im transnationalen Raum. Rechtsgeschichte, n. 8, p. 14-32, 2006.

AMSTUTZ, Marc; KARAVAS, Vaios. Weltrecht: Ein Derridasches Monster. In: CALLIESS, Gralf-Peter; FISCHER-LESCANO, Andreas; WIELSCH, Dan; ZUMBANSEN, Peer (ed.). Soziologische Jurisprudenz. Festschrift für Gunther Teubner zum 65. Geburtstag. Berlin: Walter de Gruyter, 2009.

ARCHIBUGI, Daniele; HELD, David (ed.). Cosmopolitan Democracy: An Agenda for a New World Order. Cambridge: Polity Press, 1995.

AVRITZER, Leonardo. Culture, Democracy and the Formation of the Public Space in Brazil. In: SOUZA, Jessé; SINDER, Valter (ed.). Imagining Brazil. Lanham MD: Rowman \& Littlefield, 2005.

BACKER, Larry Catá. Economic Globalization and the Rise of Efficient Systems of Global Private lawmaking: Wal-Mart as Global Legislator. Universty of Connecticut Law Review, p. 1739-1784, 2007.

BORCH, Christian. Systemic Power: Luhmann, Foucault, and Analytics of Power. Acta, n. 48, 2005.

BOURDIEU, Pierre. La Noblesse d’État. Grandes Écoles et Esprit de Corps. Paris: Minuit, 1989.

BRAITHWAITE, J.; Drahos, P. Global Business Regulation. Cambridge: Cambridge University Press, 2000.

BRUNKHORST, Hauke. Constitutionalism and Democracy in the World Society. In: DOUBNER, Petra; LOUGHLIN, Martin (ed.). The Twilight of Constitutionalism. Oxford: Oxford University Press, 2010. p. 179-98.

CHERNILO, Daniel. Social Theory's Methodological Nationalism. Myth and Reality. European Journal of Social Theory, p. 5-22, 2006.

CHERNILO, Daniel. A Social Theory of the Nation-State: The Political Forms of Modernity beyond Methodological Nationalism. Londres: Routledge, 2007. 
COHEN, Joshua; SABEL, Charles F. Global Democracy? NYU Journal of International Law and Politics, n. 37, p. 763-797, 2005.

DEAKIN, Simon. The Returno $f$ the Guild? Network Relations in Historical Perspective. In: AMSTUTZ, Marc; TEUBNER, Gunther (ed.). Networks: Legal Issues of Multilateral Cooperation. Oxford: Hart Publishing, 2009. p. 53-73.

DILLING, Olaf; HERBERG, Martin; WINTER, Gerd. Responsible Business. Self-Governance and Law in Transnational Economic Transactions. Oxford: Hart Publishing, 2008.

EDER, Klaus. Zur Transformation nationalstaatlicher Öffentlichkeit in Europa. Von der Sprachgemeinschaft zur issue spezifischen Kommunikationsgemeinschaft. Berliner Journal für Soziologie, n. 10, p. 167-184, 2000.

EDER, Klaus; TRENZ, Hans J. The democratising dynamics of an European public sphere. Towards a theory of democratic functionalism. European Journal of Social Theory, n. 7, p. 5-25, 2004.

GRABHER, Christoph Beat. Wanjina and Wunggurr: The Propertisation of Aboriginal Rock Art under Australian Law. In: CALLIESS, Gralf-Peter; FISCHER-LESCANO, Andreas; WIELSCH, Dan; ZUMBANSEN, Peer (ed.). Soziologische Jurisprudenz. Festschrift für Gunther Teubner zum 65. Geburtstag, 2009.

FORST, Rainer. Das Recht auf Rechtfertigung - Elemente einer konstruktivistischen Theorie der Gerechtigkeit. Frankfurt aM: Suhrkamp Verlag, 2007.

FOUCAULT, Michel. II faut défendre la Société. Cours au Collége de France, 1975-76. Paris: Gallimard, 1997.

FOUCAULT, Michel. Security, Territory, Population. Lectures at the Collège De France 1977-78. Basingstoke: Palgrave Macmillan, 2007.

HABERMAS, Jürgen. Theorie des kommunikativen Handelns. Band 1. Handlungsrationalität und gesellschaftliche Rationalisierung. Frankfurt aM: Suhrkamp Verlag, 1981.

HABERMAS, Jürgen. Strukturwandel der Öffentlichkeit. Untersuchungen zu einer Kategorie der bürgerlichen Gesellschaft. Frankfurt aM: Suhrkamp Verlag, [1962] 1990.

HABERMAS, Jürgen. Faktizität und Geltung. Beiträge zur Diskurstheorie des Rechts und des demokratischen Rechtsstaats. Frankfurt aM: Suhrkamp Verlag, 1992.

HARSTE, Gorm. Modernitet og Organisation. Copenhagen: Forlaget Politisk Revy, 1997.

HEGEL, Georg W. F. Grundlinien der Philosophie des Rechts. Oder Naturrecht und Staatswissenschaft im Grundrisse. Frankfurt aM-Hamburg: Fischer Bücherei, [1821] 1968.

HEGEL, Georg W. F. Grundlinien der Philosophie des Rechtsoder Naturrecht und Staatswissenschaft im Grundrisse Werke. Band 7. Frankfurt aM: Suhrkamp Verlag, [1821] 1970.

HEGEL, Georg W. F. Die Verfassung Deutschlands. In: HEGEL, Georg W. F. Gesammelte Werke. Band 1. Frankfurt aM: Suhrkamp Verlag, [1800-02] 1971. p. 451-610. 
HERBERG, Martin. Globalisierung und private Selbstregulierung. Umweltschutz in multinationalen Unternehmen. Frankfurt aM: Campus Verlag, 2007.

HERBERG, Martin. Global Legal Pluralism and Interlegality: Environmental Self-Regulation in Multinational Enterprises as Global Law-Making. In: DILLING, Olaf; HERBERG, Martin; WINTER, Gerd (ed.). Responsible Business. Self-Governance and Law in Transnational Economic Transactions. Oxford: Hart Publishing, 2008. p. 17 - 40.

HELD, David; KOENING-ARCHIBUGI, Mathias (ed.). Global Governance and Public Accountability. Oxford: Blackwell Publishing, 2005.

HÖFFE, Otfried. Demokratie im Zeitalter der Globalisierung. Munich: CH Beck Verlag, 1999.

HOLZER, Boris. Governance without Politics? Administration and Politics in the Basel II Process. In: STRULIK, Torsten; WILKE, Helmut (ed.). Towards a Cognitive Mode in Global Finance. The Governance of a Knowledged-Based Financial System. Frankfurt aM: Campus Verlag, 2006. p. 259-278.

JOERGES, Christian; EVERSON, Michelle. The European Turn to Governance and Unanswered Questions of Legitimacy: Two Examples and Counter-intuitive Suggestions. In: JOERGES, Christian; STRÅTH, Bo; WAGNER, Peter (ed.). The Economy as a Polity. The Political Constitution of Contemporary Capitalism. London: UCL Press, 2005. p. 159-180.

KARAVAS, Vagias. Digitale Grundrechte. Elemente einer Verfassung des Informationsflusses im Internet. Baden-Baden: Nomos Verlag, 2007.

KINGSBURY, Benedict; KRISCH, Nico; STEWART, Richard B. The Emergence of Global Administrative Law. Law and Contemporary Problems, n. 68, p. 15-62, 2005.

KJAER, Poul F. The Societal Function of European Integration in the Context of World Society. Soziale Systeme - Zeitschrift für Soziologische Theorie, n. 13, p. 367-378, 2007.

KJAER, Poul F. Three Forms of Governance and Three Forms of Power. In: ERIKSEN, Erik Oddvar; JOERGES, Christian; RÖDL, Florian. Solidarity in a Post-national Union. The Unsettled Political Order of Europe. London: Routledge, 2008.

KJ/ER, Poul F. Embeddedness through Networks - a Critical appraisal of the Network Concept in the Oeuvre of Karl-Heinz Ladeur. German Law Journal, n. 10, p. 483-499, 2009a.

KJAER, Poul F. Post-Hegelian Networks: Comments on the Chapter by Simon Deakin. In: AMSTUTZ, Marc; TEUBNER, Gunther (ed.). Networks: Legal Issues of Multilateral Cooperation. Oxford: Hart Publishing, 2009b. p. 75-85.

KJAER, Poul F. The Metamorphosis of the Functional Synthesis. Wisconsin Law Review, v. 4, n. 1, p. 489-533, 2010a.

KJAER, Poul F. The Structural Transformation of Embeddedness. 2010b.

KJ/ER, Poul F. Between Governing and Governance: On the Emergence, Function and Form of Europe's Post-national Constellation. Oxford: Hart Publishing, 2010c. 
KJAER, Poul F. Law and Order Within and Beyond National Configurations. In: KJAER, Poul F.; TEUBNER, Gunther; FEBBRAJO, Alberto (ed.). The Financial Crisis in Constitutional Perspective: The Dark Side of Functional Differentiation, 2011.

KRASNER, Stephen D. Structural Causes and Regime Consequences: Regimes as Intervening Variables. In: KRASNER, Stephen D. (ed.). International Regimes. Ithaca NY: Cornell University Press, 1983.

KNÖBL, Wolfgang. Of Contingencies and Breaks: The US American South as an Anomaly in the Debate on Multiple Modernities. XLVII Archives Européennes de Sociologie, p. 125157, 2006.

LADEUR, Karl-Heinz. Towards a Legal Theory of Supranationality - The Viability of the Network Concept. European Law Journal, n. 3, p. 33-54, 1997.

LADEUR, Karl-Heinz. Der Staat gegen die Gesellschaft. Zur Verteidigung der Rationalität der Privatsrechtsgesellschaft. Tübingen: Mohr Siebeck, 2006.

LEIBFRIED, Stephan; ZÜRN, Michael (ed.). Transformation of the State? Cambridge: Cambridge University Press, 2005.

LIEKWEG, Tania. Das Recht der Weltgesellschaft. Systemtheoretische Perspektiven auf die Globalisierung des Rechts am beispiel der lex mercatória. Stuttgart: Lucius \& Lucius, 2003.

LUHMANN, Niklas. Die Weltgesellschaft. Archiv für Rechts- und Sozialphilosophie, n. 57, p. 1-35, 1971.

LUHMANN, Niklas. Rechtssoziologie. Opladen: Westdeuscher Verlag, [1972] 1983.

LUHMANN, Niklas. Macht. Stuttgart: Ferdinand Enke Verlag, [1975] 1988.

LUHMANN, Niklas. Das Recht der Gesellschaft. Frankfurt aM: Suhrkamp Verlag, 1993.

LUHMANN, Niklas. Die Zukunft der Demokratie. In: LUHMANN, Niklas. Soziologische Aufklärung 4. Beiträge zur Funktionalen Differenzierung der Gesellschaft. Opladen: Westdeutscher Verlag, 1994. p. 126-132.

LUHMANN, Niklas. Kausalität im Süden. 1 Soziale Systeme. Zeitschrift für Soziologische Theorie, 1995.

LUHMANN, Niklas. Die Gesellchaft der Gesellschaft. Frankfurt aM: Suhrkamp Verlag, 1997. LUHMANN, Niklas. Organisation und Entscheidung. Opladen-Wiesbaden: Westdeutscher Verlag, 2000a.

LUHMANN, Niklas. Die Politik der Gesellschaft. Frankfurt aM: Suhrkamp Verlag, $2000 \mathrm{~b}$.

MESTMÄCKER, Ernst-Joachim. Zur Wirtschaftsverfassung in der Europäischen Union. In: MESTMÄCKER, Ernst-Joachim. Wirtschaft und Verfassung in der Europäischen Union. Baden-Baden: Nomos Verlag, 2003. p. 507- 537.

NEVES, Marcelo. Verfassung und Posivität des Rechts in der peripheren Moderne. Berlin: Duncker \& Humblot, 1992. 
NEYER, Jürgen. The Justice Deficit of the EU and other International Organisations. In: JOERGES, Christian; KJ/ER. Poul F. (ed.). Transnational Standards of Social Protection: Contrasting European and International Governance. Oslo: Arena Report Series, 2008. n. 5, p. 199-222.

NEYER, Jürgen. Justice, Not Democracy. Legitimacy in the European Union. Journal of Common Market Studies, n. 48, p. 903-21, 2010.

NICKEL, Rainer. Legal Patterns of Global Governance: Participatory Transnational Governance. CLPE Research Paper, v. 2, n. 1, 2006.

NICOL, Danny. The Constitutional Protection of Capitalism. Oxford: Hart Publishing, 2010.

PARSONS, Talcott. The System of Modern Societies. Englewood Cliffs NJ-Hemel Hempstead: Prentice-Hall, 1971.

RUBIN, Edward L. Getting Past Democracy. University of Pennsylvania Law Review, n. 149, p. 711-792, 2001.

SASSEN, Saskia. Territory, Authority, Rights: From Medieval to Global Assenblages. Princeton NJ: Princeton University Press, 2006.

SAVIGNY, Friedrich Carl von. Geschichte des Römischen Rechts im Mittelalter. Bd. 5. Bad Homburg, 1961.

SAVIGNY, Friedrich Carl von. System des heutigen Römischen Rechts. Bearb. von O.L. Heuser - 2. Aufl. Berlim, 1974.

SCHMITT, Carl. Der Nomos der Erde. Im Völkerrecht des Jus Publicium Europaeum. Berlin: Dunker \& Humblot, 1950.

SINCLAIR, Timothy J. Global Monitor: Bond Rating Agencies. New Political Economy, n. 8, p. 147-161, 2003.

SLAUGHTER, Anne-Marie. A New World Order. Princeton NJ: Princeton University Press, 2004.

STEFFEK, Jens. Tales of Function and Form: The Discursive legitimation of International Technocracy. Normative Orders Working Paper, n. 2, 2011.

STICHWEH, Rudolf. Strukturbildung in der Weltgesellschaft - Die Eigenstrukturen der Weltgesellschaft und die Regionalkulturen der Welt. In: Thomas Schwinn (ed.). Die Vielfalt und Einheit der Moderne. Kulturund strukturverglelchende Analysen. Wiesbaden: Verlag für Sozialwissenschaften, 2006.

STICHWEH, Rudolf. Dimensionen des Weltstaats im System der Weltpolitik. In: ALBERT, Mathias; STICHWEH, Rudolf (eds.). Weltstaat und Weltstaatlichkeit. Beobachtungen globaler politischer Strukturbildung. Wiesbaden: Verlag für Sozialwissenschaften, 2007. p. 25-36.

STICHWEH, Rudolf. Das Konzept der Weltgesellschaft: "Genese und Strukturbildung eines globalen Gesellschaftssystems". Rechtstheorie, n. 39, 2008. 
TEUBNER, Gunther. Reflexives Recht: Entwicklungsmodelle des Rechts in vergleichender Perspektive. Archiv für Rechts- und Sozialphilosophie, n. 68, p. 13-59, 1982.

TEUBNER, Gunther (ed.). Global Law without a State. Aldershot: Ashgate-Dartmouth Publishing, 1997.

TEUBNER, Gunther. Globale Zivilverfassungen: Alternativen zur staatszentrierten Verfassungstheorie. Zeitschrift für ausländisches öffentliches Recht und Völkerrecht, $n$. 63, p. 1-28, 2003.

TEUBNER, Gunther; FISCHER-LESCANO, Andreas. Regime-Kollisionen: Zur Fragmentierung des globalen Rechts. Frankfurt aM: Suhrkamp Verlag, 2006.

TEUBNER, Gunther; FISCHER-LESCANO, Andreas. Regime-Collisions: The Vain Search for Legal Unity in the Fragmentation of Global Law. Michigan Journal of International Law, p. 999-1045, 2004.

THOMPSON, Grahame. Tracking Global Corporate Citizenship: Some Reflections on 'Lovesick' Companies. IIIS Discussion Paper, n. 192, 2006.

TULLY, James. Strange Multiplicity. Constitutionalism in an Age of Diversity. Cambridge: Cambridge University Press, 1995.

TULLY, James. The Imperialism of Modern Constitutional Democracy. In: WALKER, Neil; LOUGHLIN, Martin (ed.). The Paradox of Constitutionalism: Constituent Power and Constitutional Form. Oxford: Oxford University Press, 2007.

WALK, Heike. Formen Politischer Institutionalisierung: NGOs als Hoffnungsträger globaler Demokratie. In: BECKERT, Jens; ECKERT, Julia; KOHLI, Martin; STREECK, Wolfgang (ed.). Transnationale Solidarität. Chancen und Grenzen. Frankfurt aM: Campus Verlag, 2004. p. 163-180.

WALKER, Neil. Beyond boundary disputes and basic grids: Mapping the global disorder of normative orders. International Journal of Constitutional Law, n. 6, p. 373-396, 2008.

WALLERSTEIN, Immanuel. World-Systems Analysis. An Introduction. Durham NC: Duke University Press, 2004.

WALTER, Christian. Constitutionalizing (Inter)national Governance: Possibilities for and Limits to the Development of an International Constitutional Law. German Yearbook of International Law, n. 44, 2001.

WEBER, Max. Bureaucracy. In: GERTH, H. H.; MILLS, C. Wright (ed.). From Max Weber: Essays in Sociology. New York: Oxford University Press, 1946.

WERRON, Tobias. Der Weltsport und sein Publikum. Zur Autonomie und Entstehung des modernen Sports. Weilerswist: Velbrueck Verlag, 2009.

WIENER, Antje. The Invisible Constitution of Politics: Contested Norms and International Encounters. Cambridge: Cambridge University Press, 2008. 
WOLF, Klaus Dieter; FLOHR, Annegret; RIETH, Lothar; SCHWINDENHAMMER, Sandra. The Role of Business in Global Governance. Corporations as Norm- entrepreneurs. Basingstoke: Palgrave Macmillan, 2010.

ZÜRN, Michael. Politik in der postnationalen Konstellation. Über das Elend des methodologischen Nationalismus. In: LANDFRIED, Christine (ed.). Politik in einer entgrenzten Welt. Kongreß der Deutschen Vereinigung für Politische Wissenschaft. Cologne: Verlag Wissenschaft und Politik, 2001. p. 181-204.

KJAER, Poul F. O sentido do político na concepção do transconstitucionalismo: uma perspectiva sociológica.

RBSD - Revista Brasileira de Sociologia do Direito, v. 6, n.

3, p. 30-69, set./dez. 2019. 